\title{
An unprecedented increase in burn injuries due to alcohol-based hand sanitizers during the COVID-19 outbreak
}

\author{
Mostafa Dahmardehei ${ }^{1}$, Majid Khadem Rezaiyan ${ }^{2}$, Farhang Safarnejad ${ }^{3}$, Ali Ahmadabadi ${ }^{4}$ (D) \\ Received: 1 Nov 2020 \\ Published: 23 Aug 2021
}

\section{Abstract}

Background: Due to the COVID-19 outbreak, protective measures including alcohol-based hand rub, received unexampled popularity in Iran. Alcohol hand rub is effective, inexpensive and simple to use, but it is a flammable liquid, which might cause burn injuries. In this study, we investigated burn injuries due to alcohol hand sanitizers during the COVID-19l disease outbreak in Iran.

Methods: This cross-sectional study was performed on burn patients referred to Motahari Burns and Reconstruction Center from February 20th, 2020 (official announcement of the epidemic of COVID-19 in Iran) up to April 19th, 2020. All outpatients and hospitalized burn injuries caused by alcohol during the abovementioned period were included.

Results: There were 76 burn injuries due to the use of alcohol hand sanitizer. Sixty patients were treated outpatient, and 16 were hospitalized. The mean \pm SD age of patients was 33.2 \pm 17.9 years and most were males (57 individuals, $75 \%$ ). Also, the mean \pm SD of TBSA was $6.1 \pm 6.5 \%$. In hospitalized ones, the mean \pm SD hospital stay was $11.7 \pm 8.6$ days. The most burnt area was the head (39.5\%) followed by the right upper limb (35.5\%) and the left upper limb (23.7\%). Patients were actively engaged in burn injury in $61.8 \%$ of cases, while they were passively burnt in $34.2 \%$ of cases and in $3.9 \%$ the mechanism was unknown. Burn injuries mostly happened in the yard (22.4\%) followed by the rooftop $(21.1 \%)$ and outdoors $(18.4 \%)$.

Conclusion: Appropriate general education, especially through mass media, can reduce burns caused by alcohol-based sanitation during the COVID-19 outbreak. Most of these burn injuries involved face and hands, which are cosmetically and functionally important.

Keywords: Alcohol-Based Hand Sanitizer, COVID-19 Outbreak, Burns

Conflicts of Interest: None declared

Funding: None

*This work has been published under CC BY-NC-SA 1.0 license.

Copyright $\subseteq$ Iran University of Medical Sciences

Cite this article as: Dahmardehei M, Khadem Rezaiyan M, Safarnejad F, Ahmadabadi A. An unprecedented increase in burn injuries due to alcoholbased hand sanitizers during the COVID-19 outbreak. Med J Islam Repub Iran. 2021 (23 Aug);35:107. https://doi.org/10.47176/mjiri.35.107

\section{Introduction}

After the COVID-19 disease pandemic, World Health Organization (WHO) recommended frequent alcoholbased hand rub as one of the most effective preventive measures in the community (1). The first case of patient with COVID-19 in Iran was reported on February $20^{\text {th }}$, 2020 (2), and soon after, Iran wa s considered as one of the highest risk areas (3). Public education about protective measures was initiated. Alcohol-based hand sanitizer then became popular in Iran.

Alcohol has an immediate and excellent activity against

\section{Corresponding author:Dr Ali Ahmadabadi, ahmadabadia@mums.ac.ir}

1. Burns Research Center, Iran University of Medical Sciences, Tehran, Iran

2. Clinical Research Development Unit, Mashhad University of Medical Sciences, Mashhad, Iran

3. Department of Surgery, Kurdistan University of Medical Sciences, Sanandaj, Iran

4. Surgical Oncology Research Center, Mashhad University of Medical Sciences, Mashhad, Iran many viruses, including coronavirus (4). Hand hygiene is considered an effective practice in reducing respiratory, gastrointestinal and skin infections. Handwashing with water and soap is recommended for dirty hands, and decontamination by alcohol-based hand sanitizers for hands without gross contamination $(1,5)$.

Nonetheless, alcohol is a flammable liquid, and the $\mathrm{Na}-$ tional Fire protection association classified ethyl alcohol in Class IB flammable and combustible liquids with a flashpoint of $<73{ }^{\circ} \mathrm{F}\left(22.8^{\circ} \mathrm{C}\right)$ and boiling point $\geq 100{ }^{\circ} \mathrm{F}$

$\uparrow$ What is "already known" in this topic:

Alcohol is a flammable liquid. Burns related to other alcoholbased products have been reported in some studies, but burns related to alcohol-based hand rubs have not been studied yet.

$\rightarrow$ What this article adds:

Careless use of alcohol-based hand sanitizer during the COVID-19 pandemic may increase burn injuries. 
$\left(37.8{ }^{\circ} \mathrm{C}\right)(6)$. The flashpoint is the lowest temperature at which a volatile liquid can vaporize to form an ignitable mixture with air. As the density of ethanol is higher than air, in areas without air-conditioning, ethanol vapor may accumulate at lower levels. Any electrical spark or burning flame may ignite this ethanol-air mixture (7).

Burns caused by alcohol have been reported in some investigations. Fire and burns in the operating room after skin preparation with alcohol-based solutions and use of electrocautery have been reported in the literature $(8,9)$. Also, alcohol drinking has been related to burn injuries $(10,11)$. In some reports, up to $20 \%$ of burns referred to a burn center were alcohol-related injuries (12). In this study, we investigated burn injuries caused by alcohol hand sanitizers during the COVID-19 outbreak in Iran.

\section{Methods}

This study was performed on burn patients referred to Motahari Burns and Reconstruction Center affiliated to Iran University of Medical Sciences, Tehran, Iran, from February $20^{\text {th }}, 2020$ (official announcement of starting the epidemic of COVID-19 in Iran) up to April $19^{\text {th }}, 2020$.

All outpatients and hospitalized burn injuries caused by alcohol during the above-mentioned period were included. After few days of starting the COVID-19 pandemic, we observed an unexpected increase in burn injuries caused by alcohol hand sanitizer and data gathering was started by a checklist.

Data were analyzed by SPSS 16 (SPSS Inc. Chicago, Il, The USA) using descriptive (mean, standard deviation, range, frequency, percentage) and inferential analysis (ANOVA, student t-test and Chi-squared test). All tests were two-tailed and P-value below 0.05 was considered statistically significant.

\section{Results}

Overall, 2198 patients were referred to our burn center during these two consecutive months. There were 76 burn injuries $(3.45 \%)$ following the use of alcohol hand sanitizer. In hospitalized patients (294 cases), 16 injuries $(5.44 \%)$ were due to alcohol hand rub. Besides, there were 1904 outpatient admissions in the emergency department, of whom $60(3.15 \%)$ were due to alcohol hand sanitizer. Demographic data are summarized in Table 1 . The most burnt area was the head $(39.5 \%)$ followed by the right upper limb (35.5\%) and left upper limb (23.7\%).

Patients were actively engaged in burn injury in $61.8 \%$ of cases, while they were passively involved in $34.3 \%$ of cases, and in $3.9 \%$ the mechanism was unknown. Burn injuries mostly happened in the yard $(22.4 \%)$, followed by the rooftop (21.1\%) and outdoors (18.4\%) (Fig. 1).

The time trend of alcohol-related burn injuries is showed four peaks, of which three are well known; the day of nature (equals to $13^{\text {th }}$ Farvardin in Persian calendar), Fireworks Wednesday (Chaharshanbeh Suri, the last Wednesday before the New Year), and the first day of the New Year in the Persian calendar.

Twelve patients $(15.8 \%)$ underwent excision and skin auto-graft, three $(3.9 \%)$ needed biologic dressing, and one (1.3\%) escharotomy followed by excision and skin grafting. No amputation or fatality was reported.

An online visit program was scheduled. Patients were advised not to come back to the hospital unless a direct visit or dressing change is inevitable. These measures led to about a $60 \%$ decrease in outpatient visits and a $48 \%$ decrease in hospitalized patients in our center.

\section{Discussion}

Considering the religious and legal bans for alcohol drinking, alcoholic beverages are used rarely in this coun-

Table 1. Demographic characteristics of alcohol-related burn injuries

\begin{tabular}{lccc}
\hline Demographic variable & Minimum & Maximum & Mean \pm SD \\
\hline Age (year) & 2 & 87 & $33.2 \pm 17.9$ \\
TBSA (\%) & 4 & 36 & $6.1 \pm 6.5$ \\
Hospital stay (day) ${ }^{*}$ & 2 & 37 & $11.7 \pm 8.6$ \\
Sex (male) & & & $57(75 \%)$ \\
Third-degree burns & & & $12(15.8 \%)$ \\
\hline Only in hospitalized patients & &
\end{tabular}

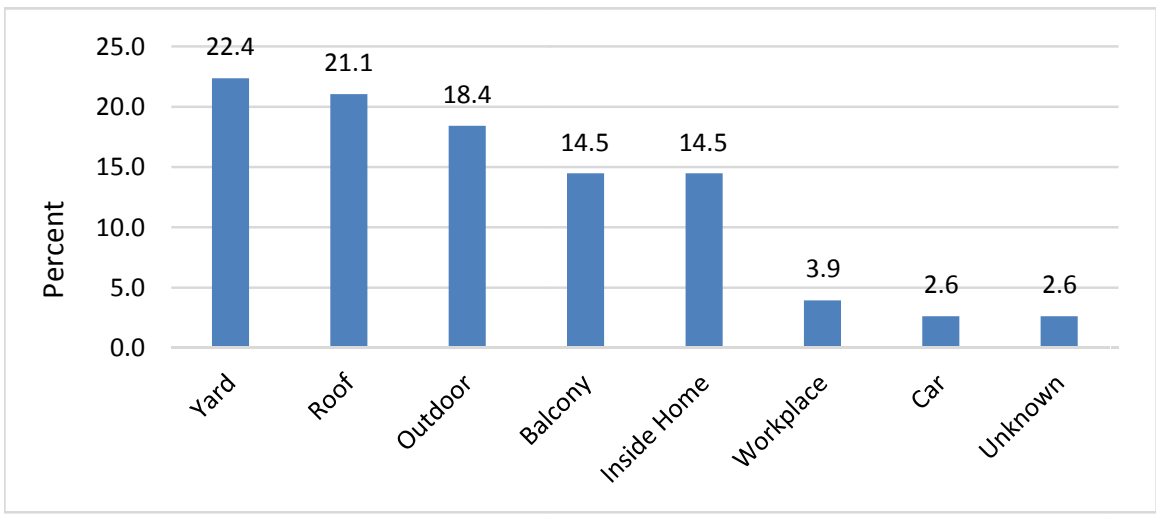

Fig. 1. Distribution (percent) of the location of burns due to alcohol hand rub 
try, and burn injury related to alcohol intoxication is a rare accident. In total, 1984 acute burn patients were hospitalized in Motahari Burns and Reconstruction Hospital (Tehran, Iran) during 2019, only four patients had a documented history of alcohol use, and burns in three patients were related to alcohol misuse as a fire accelerant.

After the COVID-19 disease outbreak, alcohol-based hand rubs became accessible almost anywhere. Therefore, during the first two months after the COVID-19 outbreak, we admitted 76 burn injuries caused by alcohol hand sanitizers. Most of them were small burns. In 60 patients, the mean \pm SD of TBSA was $3.95 \%$, and they were treated outpatient. Nevertheless, in 16 patients, the mean \pm SD of burnt TBSA was $14.4 \%$; among them, 13 patients had at least one anatomical area with third-degree burns. These patients were hospitalized with a mean hospital stay of 11.7 days. All of them were treated by wound excision and skin autograft. There was no mortality.

Regarding the mechanism of injury, pouring alcohol on existing fire or applying alcohol as a fire starter was responsible in 48 patients. Twenty-six patients were injured by pouring alcohol on fire or applying alcohol as a fire accelerant. Nevertheless, 22 were bystanders and injured passively by others. When a flammable liquid such as ethanol is poured onto a burning fire, it catches fire. Then the flame may spread into the container leading to more ignition. After ignition, a sudden volume expansion occurs and the remained liquid in the container is quickly egressed through the container opening (7). It happens so quickly, in which victims have no chance to avoid the burning liquid.

Approaching a heater, fireplace or fire, while hands are wet by alcoholic hand rub can lead to a burn injury. Ten patients were injured by this mechanism. Alcohol burns with a bluish color flame and due to low luminance, it is difficult to see its flame, especially in the day time (7). This may lead to a delay in extinguishing the fire.

Two patients applied alcoholic hand rubs on their faces and experienced burn injury while smoking. Five patients applied huge amounts of alcohol inappropriately for disinfection of surfaces in their home, workplace and even inside of their car. Accumulation of alcohol vapor in a closed area led to a burn injury. Our study was conducted in the last month of winter and the first month of spring. In the second half of the spring and summer, when the weather gets warmer, alcohol vapors more rapidly within open containers and can lead to more accidents. In public education, it is especially important to inform people not to leave the alcohol bottle inside the car on a warm day under sunlight. It must also be emphasized to recap the alcohol container as soon as possible after use.

Three other patients tried to decontaminate their clothes with alcoholic hand rubs and experienced a fire accident. Two of them were injured severely (burnt TBSA, 18\% and $20 \%$ ) and were hospitalized and underwent wound excision and skin autograft.

Flame cannot pass through orifices smaller than 0.9 $\mathrm{mm}$, so it is suggested to build alcohol containers with such a small orifice. Then no flame is capable of igniting the alcohol within the container and cause severe fire ac- cidents (7).

Most patients (57 persons, 77\%) were injured in the household area. Quarantine measures and physical distance regulations were implemented in Iran soon after the COVID-19 outbreak as recommended by the World Health Organization for areas where COCID-19 is circulating (13). Therefore, most people stayed at home during this period.

Most injuries involved the face and the upper extremities, especially hands. Most patients were injured while pouring alcohol on the fire, sttarting a fire by alcohol or while their hands were near a fire source after alcohol hand rub. Hence, hands were injured in most cases.

Burns in the face occurred more commonly in patients who were sitting near the fire and were passively injured when another person poured alcohol hand sanitizer on fire or in bystander children who were standing near (10 patients).

While old persons are more at risk for complications of COVID-19 infection (14), they have an impaired cognitive and motor function and are at risk for all types of injuries, including burns. In filve elderly patients injured passively, feet were also involved. Concerning the high prevalence of diabetes in this age group, burn injury in the lower extremities can be a complicating or even limb or life-threatening injury (15). Again, education may have a pivotal role in the prevention of lower limb burn injury in this important age group.

\section{Conclusion}

In conclusion, alcohol hand rub is an effective, inexpensive, and simple method for disinfection, but it can cause burn injury. Appropriate general education, especially through mass media, can reduce burns caused by this new emerging mechanism of burn injury. Most of these burn injuries involved face and hands which are cosmetically and functionally important.

\section{Acknowledgment}

The authors gratefully acknowledge the contribution of Mr. Reza Naser Khaki to help with data gathering.

\section{Conflict of Interests}

The authors declare that they have no competing interests.

\section{References}

1. World Health Organization. Rational use of personal protective equipment (PPE) for coronavirus disease (COVID-19), Interim guidance 19 March 2020.

2. https:/www.worldometers.info/coronavirus/country/iran/

3. Repici A, Maselli A, Colombo M, Gabbiadini R, Spadaccini M, Anderloni A, et al. Coronavirus (COVID-19) outbreak: what the department of endoscopy should know. Gastrointest Endosc. 2020.

4. Rabenau HF, Kampf G, Cinatl J, Doerr HW. Efficacy of various disinfectants against SARS coronavirus. J Hosp Infect. 2005;61(2):107-111.

5. Bloomfield SF, Aiello AE, Cookson B, O'Boyle C, Larson EL. The effectiveness of hand hygiene procedures in reducing the risks of infections in home and community settings including handwashing and alcohol-based hand sanitizers. Am J Infect Control. 2007;35(10:Supplement 1):S27-S64. 
6. https://www.greatamericaninsurancegroup.com/docs/default-source/ loss-prevention/f13826-(3-08)nfpa-classificationsofflammable.pdf? sfvrsn=db6a77b1 4

7. Log T, Moi AL. Ethanol and Methanol Burn Risks in the Home Environment. Int J Environ Res Public Health. 2018;15:2379.

8. Tooher R, Maddern G, Simpson J. Surgical fires and alcohol-based skin preparations. ANZ J Surg. 2004;74(5):382-385.

9. Chae SB, Kim WK, Yoo CJ, Park CW. Fires and Burns Occurring in an Electrocautery after Skin Preparation with Alcohol during a Neurosurgery. J Korean Neurosurg Soc. 2014;55(4):230-233.

10. Palmu R, Partonen T, Suominen K, Vuola J, Isometsä E. Alcohol use and smoking in burn patients at the Helsinki Burn Center. Burns. 2018;44(1):158-167.

11. Davis CS, Esposito TJ, Palladino-Davis AG, Rychlik K, Schermer $\mathrm{CR}$, Gamelli RL, et al. Implications of alcohol intoxication at the time of burn and smoke inhalation injury: an epidemiologic and clinical analysis. J Burn Care Res. 2013;34(1):120-126.

12. Holmes WJM, Hold Ph, James MI. The increasing trend in alcohol-related burns: It's impact on a tertiary burn centre. Burns. 2010;36(6):938-943.

13. World Health Organization, Considerations for quarantine of individuals in the context of containment for coronavirus disease (COVID-19), 19 March 2020

14. Mohamadi M, Goodarzi A, Aryannejad A, Fattahi N, AlizadehKhoei M, Miri S, et al. Geriatric challenges in the new coronavirus disease-19 (COVID-19) pandemic: A systematic review. Med J Islam Repub Iran. 2020;34(1):841-848.

15. Dahmardehei M, Kazemikhoo N, Vaghardoost R, Mokmeli S, Momeni M, Nilforoushzadeh MA, et al. Effects of low level laser therapy on the prognosis of split-thickness skin graft in type 3 burn of diabetic patients: a case series. Lasers Med Sci. 2016;31:497502 . 